\title{
Effect of copper sulfate on the external microbiota of adult common snook (Centropomus undecimalis)
}

\author{
Andrea M. Tarnecki ${ }^{1 *}$ (D) Noah J. Levi ${ }^{2,3}$, Matthew Resley ${ }^{4}$ and Kevan Main ${ }^{4}$
}

\begin{abstract}
Background: The environment exerts a strong influence on the fish external microbiota, with lower diversity and increased abundances of opportunistic bacterial groups characterizing cultured fish compared to their wild counterparts. Deviation from a healthy external microbiota structure has been associated with increased susceptibility to bacterial pathogens. Treatment of wild-caught broodstock with copper sulfate for the removal of external parasites is a common aquaculture practice. Despite the microbiota's importance to fish health, the effects of copper sulfate on mucosal bacterial communities and their ability to recover following this chemical treatment have not been examined. The skin microbiota of adult common snook was characterized from wild individuals (Wild), and wild-caught fish maintained in recirculating aquaculture systems (RAS) immediately following a month-long copper sulfate treatment (Captive-1), and then two-weeks (Captive-2) and 2 years (Captive-3) after cessation of copper treatment.

Results: The skin microbiota of wild fish were characterized by high diversity and taxa including Synechocococcus, SAR11, and a member of the Roseobacter clade. Bacterial diversity decreased in Captive individuals during the 2-year sampling period. Captive fish harbored greater abundances of Firmicutes, which may reflect glycan differences between aquaculture and natural feeds. Bacterial taxa with copper resistance mechanisms and indicative of metal contamination were enriched in Captive-1 and Captive-2 fish. Vibrionaceae were dominant in Captive fish, particularly immediately and 2 weeks following copper treatment. Based on our observations and previous literature, our results suggest putatively beneficial taxa amass over time in captivity. Within 2 years, Captive individuals harbored Bacillus which contains numerous probiotic candidates and the complex carbon degraders of the family Saprospiraceae. Predicted butanoate metabolism exceeded that of Wild fish, and its reported roles in immunity and energy provision suggest a prebiotic effect for fishes.

Conclusions: The mucosal microbiota contains bacterial taxa that may act as bioindicators of environmental pollution. Increases in mutualistic groups indicate a return to a beneficial skin microbiota following copper sulfate treatment. Our data also suggests that vastly different taxa, influenced by environmental conditions, can be associated with adult fish without noticeable health impairment, perhaps due to establishment of various mutualists to maintain fish mucosal health.
\end{abstract}

Keywords: Microbiota, Common snook, Aquaculture, Copper sulfate, External mucosa, Recirculating aquaculture system

\footnotetext{
* Correspondence: atarnecki@mote.org

'Marine Immunology Program, Mote Marine Laboratory, 1600 Ken

Thompson Parkway, Sarasota, FL 34236, USA

Full list of author information is available at the end of the article
}

(c) The Author(s). 2021 Open Access This article is licensed under a Creative Commons Attribution 4.0 International License, which permits use, sharing, adaptation, distribution and reproduction in any medium or format, as long as you give appropriate credit to the original author(s) and the source, provide a link to the Creative Commons licence, and indicate if changes were made. The images or other third party material in this article are included in the article's Creative Commons licence, unless indicated otherwise in a credit line to the material. If material is not included in the article's Creative Commons licence and your intended use is not permitted by statutory regulation or exceeds the permitted use, you will need to obtain permission directly from the copyright holder. To view a copy of this licence, visit http://creativecommons.org/licenses/by/4.0/. 


\section{Background}

Fish skin mucosa is the first line of defense against bacterial infections. This protective layer prevents attachment and proliferation of pathogens and provides a surface for aggregation of secreted innate immune enzymes, antimicrobial peptides, and immunoglobulins [1]. Acting as an extension of these defenses, the external mucosa maintains a diverse bacterial assemblage inhabited primarily by commensal microorganisms that help to train the fish immune system and competitively exclude pathogens [2]. Genetic factors, such as mucus composition and immune function, as well as local environmental parameters strongly influence the taxonomic structure of these bacterial communities [2-4]. Disruption of normal immune responses and microbiota structure enhance susceptibility to opportunistic bacterial pathogens normally suppressed by these mucosal defenses [5].

As the surrounding environment shapes mucosal microbiota, wild and farmed fish of the same species have distinctive bacterial community compositions [4, 6-8], with decreased bacterial diversity and increased abundance of opportunistic pathogens characterizing captive individuals. The intensive culture conditions and high organic input of aquaculture systems generate an ideal environment for proliferation of opportunistic $r$ strategists including potentially pathogenic bacteria. In recirculating aquaculture systems (RAS), disinfection methods such as ultraviolet light and ozone reduce competition with slower-growing, commensal K-strategists [9-11], and may intensify expansion of potentially harmful microbes. Although adult fish are less susceptible to opportunistic disease than larvae [11], aquaculture practices that decrease bacterial diversity in the fish microbiota relinquish previously inhabited niches within the mucosa that opportunists can colonize, thereby increasing contact rates and potentially harmful interactions between the fish host and aquatic pathogens.

The common snook (Centropomus undecimalis) is a popular sport and food fish species throughout its geographic range from Florida to Brazil. The species is sensitive to cold events, as well as harmful algal blooms, and severe occurrences lead to mortalities and the closure of this economically important fishery [12]. Current conservation efforts by the Florida Fish and Wildlife Conservation Commission (FWC) and Mote Marine Laboratory $(\mathrm{MML})$ include captive rearing of snook for release to enhance stocks, requiring collection of wild adult common snook, and transitioning them to captivity for spawning. This practice includes periods of chemical treatment (i.e., copper sulfate) aimed at removing external parasites. Copper sulfate is an effective compound, commonly used in aquaculture to prevent parasitic infections and excess algal growth [13], but its impact on bacteria is not often considered. TomPetersen et al. [14] measured a negative impact of copper on bacterial growth; however, Qian et al. [15] reported an increase in the opportunistic genus Vibrio in shrimp treated with copper sulfate. Previous studies indicate that chemical treatment alters the fish skin microbiota and increases susceptibility to bacterial disease [16]. Thus, there is potential for these treatments to exacerbate alterations of the skin microbiota already induced by captivity. Due to the intimate relationship between the microbiota and fish health, understanding the influence of these treatments on the fish microbiota is crucial to maintenance of fishes in RAS.

Despite the common snook's importance to fisheries, very little is known about the species' microbiota. Our group recently characterized the skin-associated microbiota of juvenile common snook throughout transition from captivity to the wild during stock enhancement efforts [4]. Despite vast differences in microbial assemblages between wild and captively-reared individuals, the external microbiota adapted quickly during acclimation, and within 2 days captively-reared individuals placed in the natural environment harbored a microbiota reflective of wild-caught individuals. We have also characterized the microbiota of larval common snook during the first month of development in RAS $[17,18]$. However, to our knowledge, no studies have described microbiota composition in adult common snook. The purpose of this study was to quantify, characterize, and compare external mucosal microbiota of wild and captive adult common snook following treatment with copper sulfate. We compared the external microbiota of wild snook (Wild) to broodstock transitioned into captivity at 3 sampling periods: 1) immediately following a one-month copper sulfate treatment (Captive-1), 2) 2 weeks following copper sulfate treatment (Captive-2), and 3) 2 years after copper sulfate treatment (Captive-3). These sampling points were chosen to coincide with planned spawning events at our facility, allowing for opportunistic sampling while fish were already being handled.

\section{Methods}

Wild adult common snook were captured to build captive broodstock populations. These fish were caught at various times and locations within the coastal region of western central Florida (Table 1). Following capture, fish were transported to Mote Aquaculture Research Park (MAP), Sarasota, Florida and transitioned to captivity in RAS containing 28,000 L tanks and equipped with a $0.085 \mathrm{~m}^{3}$ drop filter (Aquaculture Systems Technologies, L.L.C, New Orleans, LA) for solids removal, a $900 \mathrm{~L}$ moving bed reactor containing $0.283 \mathrm{~m}^{3}$ plastic extruded floating media $\left(\mathrm{AMB}^{\mathrm{Ts}}\right.$ media, EEC, Blue Bell, PA) for biofiltration, a protein skimmer, two $150 \mathrm{~W}$ High Output 
Table 1 Capture dates and locations of captive broodstock sampled in this study

\begin{tabular}{lllll}
\hline Fish Tag ID & Sex & Date Captured & Location Captured & Method of Capture \\
\hline 1272 & Male & O3 Jun 2016 & Snake Island, Venice, FL & Hook \& line \\
1307 & Male & O3 Jun 2016 & Snake Island, Venice, FL & Hook \& line \\
1270 & Male & 03 Jun 2016 & Snake Island, Venice, FL & Hook \& line \\
1265 & Male & 03 Jun 2016 & Snake Island, Venice, FL & Hook \& line \\
5D0D & Male & 13 May 2015 & Snake Island, Venice, FL & Hook \& line \\
1302 & Female & 03 Jun 2016 & Snake Island, Venice, FL & Hook \& line \\
3C79 & Female & 19 Nov 2012 & Bowlees Creek, Sarasota, FL & Seine net \\
1260 & Female & 03 Jun 2016 & Snake Island, Venice, FL & Hook \& line \\
7D36 & Female & 13 May 2015 & Snake Island, Venice, FL & Hook \& line \\
2B2B & Female & 19 Nov 2012 & Bowlees Creek, Sarasota, FL & Seine net
\end{tabular}

SMART HO UV units (Emperor Aquatics, Inc. ${ }^{\bullet}$, Pottstown, PA), and 126,000 btu Aquacal chiller (AquaCal AutoPilot, Inc., St Petersburg, FL). System environmental parameters were as follows: temperature $30 \pm 1{ }^{\circ} \mathrm{C}$, salinity $35 \pm 1 \mathrm{ppt}$, dissolved oxygen $5-9 \mathrm{mg} / \mathrm{L}$, and $\mathrm{pH}$ 7.5-8.4. Captive fish were maintained under a photoperiod regime of $15 \mathrm{~h}$ Light: $9 \mathrm{~h}$ Dark. Upon arrival of new broodstock in June 2016, the snook were feed trained, and once all fish were eating the systems, the systems were treated with copper sulfate pentahydrate. Copper sulfate was mixed with clean seawater from the RAS following filtration to generate a stock whose concentration varied depending on copper measurements from treated broodstock tanks. Copper stock solutions were added to increase tank concentrations by $0.1 \mathrm{ppm}$ per day until concentrations reached $0.3 \mathrm{ppm}$. Copper sulfate was added as needed to maintain at $0.3 \mathrm{ppm}$ for 30 days. Following the month-long treatment, copper levels depurated naturally from the system.

Mucus samples were collected from 10 individuals (5 males, 5 females to control for potential unknown differences between sexes) immediately following copper sulfate treatment (Captive-1; July 2016) as described below. Additional samples were collected from the same individuals 2 weeks following conclusion of copper sulfate treatment (Captive-2; August 2016). An additional sample was taken from these fish 2 years later (Captive-3; December 2018), although only 8 individuals remained due to mortality of one male and one female (5D0D and 2B2B, respectively, see Table 1) during this two-year time frame. It should be noted that fish caught prior to 2016 received previous copper sulfate treatments in our facility. The treatments prior to 2016 were at $0.2 \mathrm{ppm}$, and treatment protocols in 2016 and beyond used a target of $0.3 \mathrm{ppm}$ as this concentration increased efficacy without deleterious effects on broodstock health and reproductive performance. Fish captured in 2012 received a prophylactic treatment in November 2012 and another in February 2015 to control an outbreak of the glass anemone Aiptasia pulchella. The 2012 fish as well as the individuals caught in 2015 received a prophylactic copper sulfate treatment in November 2015. All fish in the study received the treatment described above in July 2016. In addition to samples from Captive individuals, mucus was collected from 5 male and 5 female wild common snook, caught using seine nets at Rattlesnake Key in Terra Ceia Bay, Palmetto, Florida (27.548259 N, $82.630184 \mathrm{~W}$ ) during the summer of 2016.

Fish were anesthetized and mucus collection for microbiota analysis took place opportunistically during reproductive sampling events, as previously described by Rhody et al. [19]. During this process, sterile plastic spatulas were used to delicately scrape mucus from the sides of each individual. As one person held the fish vertically, a second person gently scraped both sides of the fish from below the gills to the end of the anal fin, collecting the mucus in a sterile conical tube as it dripped from the fin. Volume of mucus collected ranged from 250 to $1500 \mu \mathrm{L}$. Samples were held on ice for further processing $(\sim 4 \mathrm{~h})$.

Mucus was vortexed thoroughly and a sterile swab was coated with the mixed mucus for microbiota characterization using high-throughput sequencing. Swabs were stored at $-80^{\circ} \mathrm{C}$ until further analysis. The use of the swab was consistent with methods previously employed in our lab to analyze common snook skin microbiota [4]. This decision was to allow comparisons with our previous study on juvenile snook [20] with as little sampling method bias as possible, as it has not been determined if freezing raw mucus alters community structure differently than freezing mucosal swabs. Bacterial counts were determined for Wild, Captive-1, and Captive-2 fishes only. Mucus remaining following swab collection was serially diluted and plated on tryptic soy agar supplemented with $2 \% \mathrm{NaCl}(\mathrm{TSA}+\mathrm{S})$ for total bacterial counts and on thiosulfate citrate bile salts sucrose agar (TCBS) for total Vibrio counts. Sucrosefermenting (yellow) and non-sucrose fermenting (green) colonies were counted separately on TCBS. 
DNA was extracted from mucosal swabs using the PowerSoil DNA Isolation Kit (Mo Bio Laboratories, Carlsbad, CA, USA) according to manufacturer protocols. The primers $515 \mathrm{~F} / 806 \mathrm{R}$ were used to amplify the V4 variable region of the $16 \mathrm{~S}$ rRNA gene with the HotStarTaq Plus Master Mix Kit (Qiagen, Valencia, CA, USA). PCR conditions were as follows: $94{ }^{\circ} \mathrm{C}$ for $3 \mathrm{~min}$, followed by 28 cycles of $94{ }^{\circ} \mathrm{C}$ for $30 \mathrm{~s}, 53{ }^{\circ} \mathrm{C}$ for $40 \mathrm{~s}$, and $72{ }^{\circ} \mathrm{C}$ for $1 \mathrm{~min}$, with a final extension at $72{ }^{\circ} \mathrm{C}$ for $5 \mathrm{~min}$. Negative controls were included in PCR reactions to assess potential reagent contamination. Resulting PCR products were pooled in equal proportion based on molecular weight and DNA concentration. Pooled products were purified with calibrated Ampure XP beads. Amplicon sequencing was performed on the Illumina MiSeq platform (Illumina, Inc., San Diego, CA, USA) following standard protocols. Sequencing was performed at MR DNA (www.mrdnalab.com, Shallowater, TX, USA). Sequences were processed using the Mothur MiSeq SOP [21] accessed on 3 May 2019 in Mothur 1.42.0. Operational taxonomic units (OTUs) were identified at 97\% similarity and classified using the Silva [22] and the GreenGenes [23] databases for functional predictions. OTUs were used as opposed to amplicon sequence variants (ASVs) to minimize methods bias during results comparisons with previous snook studies in our laboratory. The total number of sequences was standardized to the sample with the lowest coverage (23,592 sequences) prior to calculation of alpha diversity including species richness (i.e., number of OTUs) and evenness (Shannon Evenness Index).

Bacterial counts, richness, and evenness were analyzed using two-way ANOVA with sampling period and sex as main effects followed by Tukey's HSD post hoc tests where significant. Data was transformed using Box-Cox transformations to meet the assumptions of normality and homogeneity of variance. Differences between microbiota were determined using permutational analysis of variance (PERMANOVA) and similarity percentages (SIMPER) in Primer v6 [24]. Linear discriminant analysis Effect Size (LEfSe) was used to identify OTUs responsible for differences between sampling periods [25] and phylogenetic investigation of communities by reconstruction of unobserved states (PICRUSt) was used to predict microbiota function [26], with both analyses occurring in Mothur v1.42.0. Significant differences in predicted Kyoto Encyclopedia of Genes and Genomes (KEGG) pathways classified using PICRUSt were determined in STAMP v2.1.3 [27] via ANOVA followed by Tukey-Kramer post-hoc tests, using a $p$-value filter of $>0.05$ and an Effect size $<0.75$.

As this study did not include negative kit controls to account for kit reagent contamination, OTUs identified in previous research as potential contaminants $[28,29]$ were removed and data analysis was repeated as described above. Excluding potential contaminant OTUs did not change overall findings, but it did alter some genus-level observations, and these are discussed herein.

\section{Results}

\section{Culturable bacterial counts}

Total bacterial counts were highly variable among adult common snook (Table 2). Total bacterial counts were generally higher immediately following copper sulfate treatment, but these differences were not significant $\left[F_{2,24}=0.695, p=0.509\right]$. There was no detectable influence of sex on total bacterial counts $\left[F_{1,24}=0.907, p=\right.$ $0.351]$, and no interaction between sampling period and sex $\left[F_{2,24}=1.62, p=0.219\right]$. All plated dilutions on TCBS from Captive-1 individuals were too numerous to count; therefore, counts were conservatively estimated using 300 colonies per plate as follows:

$$
\begin{aligned}
\frac{C F U}{m L} & =\frac{\frac{C F U}{\text { plate }} \times \text { dilution factor }}{\text { vol.sample plated }(\mathrm{mL})}:=\frac{300 \mathrm{CFU} \times 5}{0.1 \mathrm{~mL}}: \\
& =1.5 \times 10^{4} \frac{\mathrm{CFU}}{\mathrm{mL}}
\end{aligned}
$$

Neither total nor Vibrio counts were determined for Captive- 3 fish. As Vibrio counts in Captive- 1 fish were estimated, these counts were not compared statistically with Wild or Captive-2 individuals; however, the colony counts were over 5 times higher in Captive- 1 than in Wild fishes. Captive- 2 fishes harbored over 200 times greater Vibrio counts than Wild fishes and this difference was statistically significant $\left[F_{1,16}=248, p<0.001\right]$. The data suggests a difference in Vibrio counts between sexes $\left[F_{1,16}=9.27, p=0.008\right]$, and sampled females harbored approximately $2.7 \mathrm{X}$ more Vibrio than males. The proportion of sucrose-fermenting to non-sucrose fermenting Vibrio was 2.5 and 0.5 in Wild and Captive-2 fish, respectively.

\section{Microbiota characterization}

Good's coverage values were above 0.949 in all samples, indicating a majority (95\%) of predicted OTUs in these samples were detected using high throughput sequencing. Species richness (number of OTUs) was significantly higher in Wild fish than any group of Captive fish $\left[F_{3,30}=28.5, p<0.001\right]$ (Table 3 ). Species richness decreased over time in captivity, as significantly more OTUs were identified in Captive-1 fish than Captive-3 fish. However when potential contaminants were removed, only the differences between Wild and Captive fish remained. There was no difference detected between sexes $\left[F_{1,30}=0.103, p=0.751\right]$ or for the interaction 
Table 2 Bacterial counts measured from adult common snook external mucus. $P$ values resulting from two-way ANOVA are indicated at the bottom of the table

\begin{tabular}{llll}
\hline Sampling period & Sex & Total bacterial counts (CFU/mL) & Total Vibrio counts (CFU/mL) \\
\hline Wild & Male & $4.25 \times 10^{5} \pm 1.76 \times 10^{5}$ & $1.69 \times 10^{3} \pm 1.00 \times 10^{3}$ \\
& Female & $5.30 \times 10^{5} \pm 2.85 \times 10^{5}$ & $3.89 \times 10^{3} \pm 1.53 \times 10^{3}$ \\
Captive-1 & Male & $2.71 \times 10^{6} \pm 3.83 \times 10^{6}$ & $1.50 \times 10^{4 a}$ \\
& Female & $1.40 \times 10^{6} \pm 2.11 \times 10^{6}$ & $1.50 \times 10^{4 a}$ \\
Captive-2 & Male & $3.73 \times 10^{5} \pm 1.57 \times 10^{5}$ & $3.12 \times 10^{5} \pm 2.65 \times 10^{5}$ \\
& Female & $1.45 \times 10^{6} \pm 7.23 \times 10^{5}$ & $8.46 \times 10^{5} \pm 5.24 \times 10^{5}$ \\
ANOVA & Sampling Period & $p=0.509$ & $p<0.001$ \\
& Sex & $p=0.351$ & $p=0.008$ \\
& Sampling period $\times$ Sex & $p=0.219$ & $p=0.866$ \\
\hline
\end{tabular}

${ }^{a}$ Captive-1 Vibrio counts are estimated assuming 300 colonies per plate as the results were too numerous to count

between sampling period and sex $\left[F_{3,30}=0.070, p=\right.$ $0.975]$. Wild fish had significantly greater bacterial species evenness than captive fish $\left[F_{3,30}=13.0, p<0.001\right]$, with no detectable difference between sexes $\left[F_{1,30}=\right.$ 0.046, $p=0.831]$ or interactions between these factors $\left[F_{3,30}=0.921, p=0.443\right]$.

Phylum-level classifications indicated that Proteobacteria dominated all snook sampled; however, sampling period impacted the relative abundances of identified phyla (Fig. 1). Wild snook harbored greater abundances of Alphaproteobacteria, Deltaproteobacteria, Bacteroidetes, and Cyanobacteria than their captive counterparts. Immediately following copper sulfate treatment (Captive-1), Bacteroidetes were less abundant compared to Wild fish, whereas Gammaproteobacteria, Firmicutes, and Deinococcus-Thermus were enriched. Two weeks later (Captive-2), Gammaproteobacteria made up approximately $65 \%$ of the entire mucosal microbiota. At the final sampling point 2 years later (Captive-3), Bacteroidetes sequences increased to levels more comparable to Wild fishes; however, the Firmicutes remained in high relative abundance.
PERMANOVA detected significant differences in external microbiota structure based on the interactions of sampling period and sex [Pseudo- $\left.F_{3,30}=1.23, p=0.020\right]$. Snook from each sampling period (Wild, Captive-1, Captive-2, Captive-3) harbored unique microbiota $[p$ $($ perm $) \leq 0.013] \quad$ (Fig. 2). LEfSe identified 3 OTUs enriched in Wild, 6 OTUs enriched in Captive-1, 10 OTUs enriched in Captive-2, and 7 OTUs enriched in Captive-3 (LDA > 4; see Additional file 1). Some of the most abundant ( $>5 \%$ total sequences) of these indicative OTUs included Catenococcus in Captive-1, Vibrionaceae and Idiomarina in Captive-2, and Bacillus in Captive-3 (Fig. 3). Apparent differences between sexes were only seen in Captive- 1 fish $[p$ (perm) $=0.030]$. OTUs enriched in males were primarily within the Firmicutes and included the genera Staphylococcus, Lactobacillus, and Chryseomicrobium, whereas OTUs increased in females included Gammaproteobacteria (Vibrionaceae, Catenococcus, and Shewanella) and Deinococcus-Thermus (Deinococcus).

When potential contaminating OTUs were removed from analysis, there was no detectable influence of sex

Table 3 Diversity statistics within the external microbiota of adult common snook

\begin{tabular}{llll}
\hline Sampling Period & Sex & \# OTUs & Shannon Evenness Index \\
\hline Wild & Female & $1967 \pm 971$ & $0.825 \pm 0.030$ \\
Wild & Male & $1840 \pm 334$ & $0.822 \pm 0.026$ \\
Captive-1 & Female & $568 \pm 136$ & $0.611 \pm 0.150$ \\
Captive-1 & Male & $508 \pm 129$ & $0.679 \pm 0.067$ \\
Captive-2 & Female & $400 \pm 36$ & $0.656 \pm 0.045$ \\
Captive-2 & Male & $447 \pm 64$ & $0.650 \pm 0.025$ \\
Captive-3 & Female & $405 \pm 29$ & $0.671 \pm 0.067$ \\
Captive-3 & Male & $368 \pm 20$ & $0.623 \pm 0.009$ \\
ANOVA & Sampling Period & $p<0.001$ & $p<0.001$ \\
& Sex & $p=0.559$ & $p=0.426$ \\
\hline
\end{tabular}




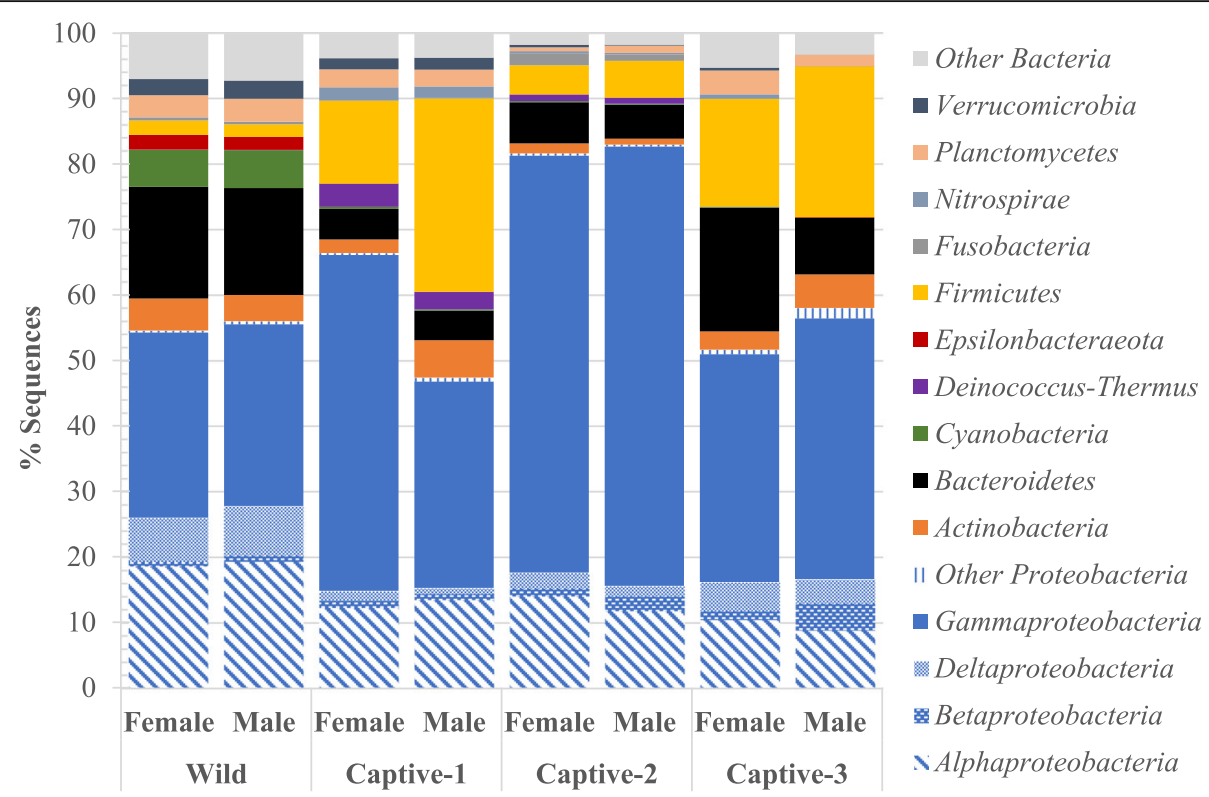

Fig. 1 Relative abundances of phyla identified in the adult common snook external microbiota

or its interaction with sampling period on total microbiota structure, but the main effect of sampling period remained (Pseudo- $F_{3,30}=11.417, p=0.001$ ). Although the general pattern of differences between all sampling periods remained, some changes occurred in the LEfSe results (see Additional File 4). The taxa Deinococcus, Staphylococcus, and Lactobacillus were removed from Captive-1 and Delftia and Bacillus were removed from Captive-3. Discriminatory taxa identified upon reanalysis included: AEGEAN-169 marine group enriched in Wild; Rhodobacteraceae and Cetobacterium enriched in Captive-2; and Aquisalimonas, Fodinibius, and an unclassified Alphaproteobacterium in Captive-3.
Less than 5\% of total bacterial sequences from Wild fish fell within taxa that contain potential fish pathogens as listed in Austin and Austin [30] (see Additional file 2), with a majority of these classified as Vibrionaceae, Arcobacter, and Acinetobacter. Potentially pathogenic taxa composed $25-30 \%$ of Captive microbiota with Vibrionaceae highly abundant at all three sampling points. Clostridium and Lactobacillus (both potential contaminants) were primarily identified in Captive-1, Halomonas and Pseudoalteromonas primarily in Captive-2, and Bacillus and Micrococcus (both potential contaminants) primarily in Captive-3. Although some of the taxa are identified as potential contaminants, they have been reported in

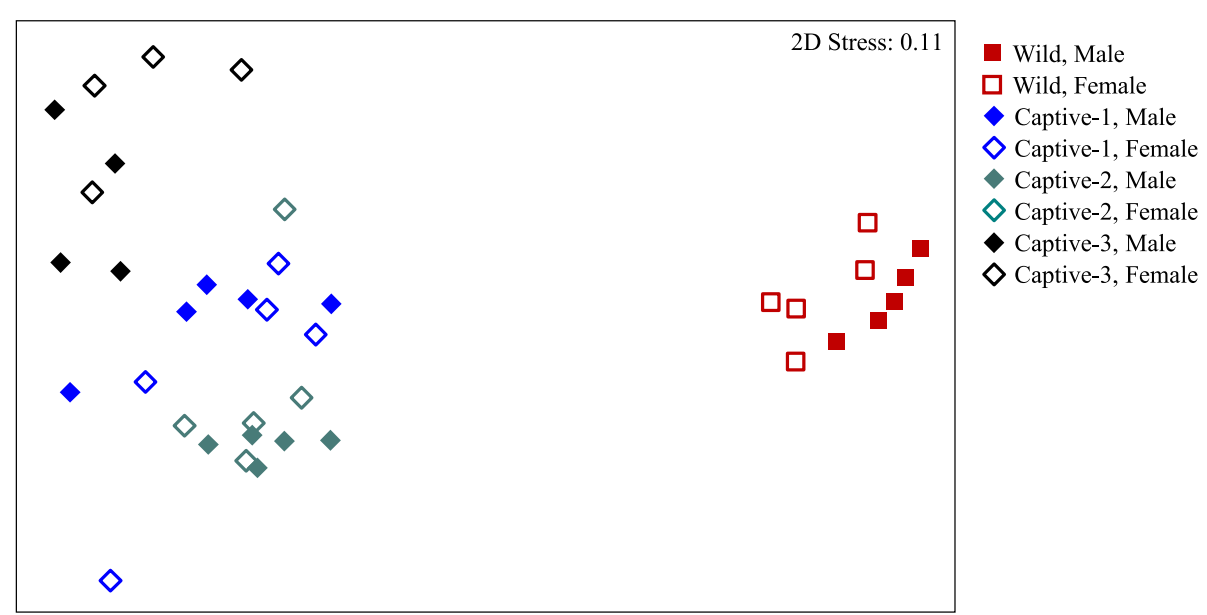

Fig. 2 Multidimensional scaling (MDS) plot relating microbiota composition to sampling period and sex 


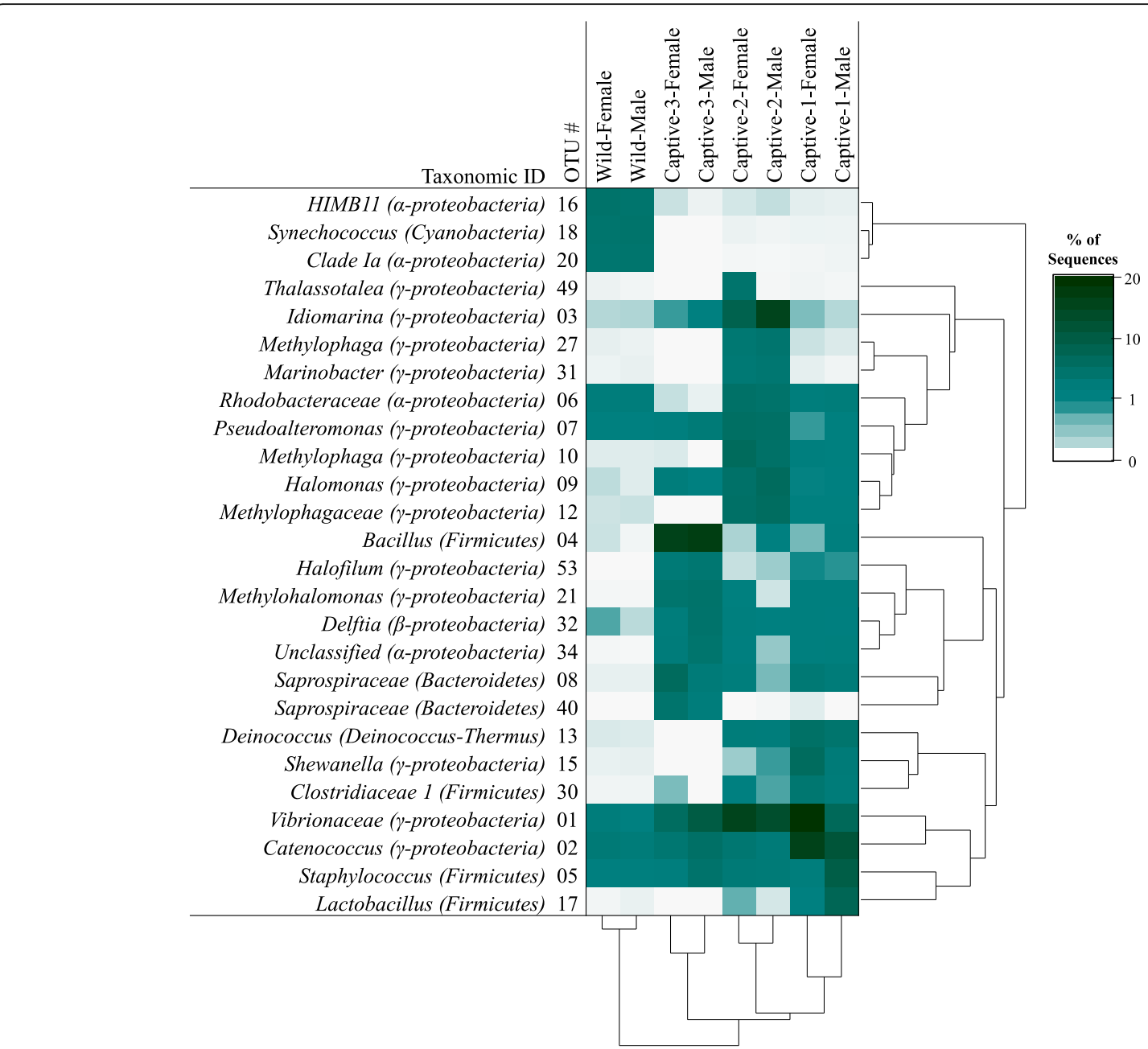

Fig. 3 Heat map indicating relative abundance of discriminatory OTUs among sampling periods

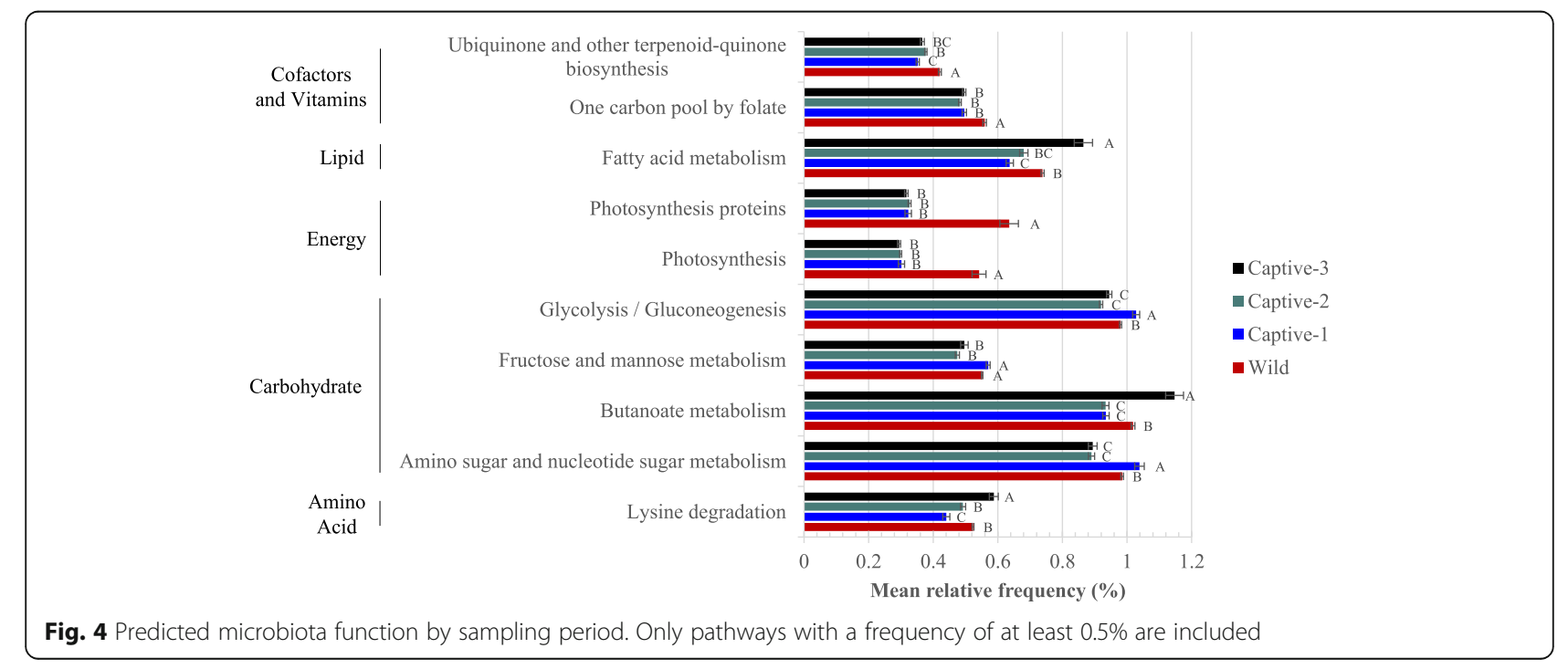


culture-based studies from the skin/gill microbiota of fishes [31-34] and therefore may be true representatives in the community.

Predicted Microbiota Function. PICRUSt analysis identified 27 pathways that were significantly altered among sampling periods, with 12 pathways having mean relative frequencies of at least $0.5 \%$ (Fig. 4), all of which fell within Level 1 Metabolism. Pathways higher in Wild fish included metabolism of terpenoids and polyketides (terpenoid backbone biosynthesis), cofactors and vitamins (one carbon pool by folate) and energy metabolism (photosynthesis, photosynthesis-antenna proteins, and photosynthesis proteins). Lipid metabolism (fatty acid metabolism) and amino acid metabolism (lysine degradation) were enriched in Captive-3 individuals. Butanoate metabolism, propanoate metabolism, and carbon fixation pathways in prokaryotes were highest in Captive-3 fish followed by Wild fishes, whereas amino sugar and nucleotide sugar metabolism and glycolysis/gluconeogenesis was increased in Captive-1 fishes followed by Wild fishes. Fructose and mannose metabolism was more abundant in Wild and Captive-1 fishes than subsequent sampling periods.

\section{Discussion}

The use of copper sulfate to remove external parasites is a common aquaculture practice. This study demonstrated that copper sulfate treatment, in combination with the RAS environment, alters the external microbiota of adult common snook as compared to their wild counterparts. We could not separate microbiota impacts from copper sulfate versus captivity alone as all fish in captivity were treated with the chemical, but changes in communities during depuration of copper from the system and enrichment of particular taxa (described below) indicate a chemical treatment effect.

We did not detect a difference in total bacterial concentrations between Wild and Captive fishes using viable plate counts (TSA + S); however, TCBS counts indicated Captive- 1 and Captive- 2 mucus contained at least 5X and 200X more Vibrio, respectively, than Wild individuals. This increase was confirmed using high-throughput sequencing as Captive- 1 and Captive-2 fish averaged $11.5 \%$ of sequences identified as Vibrionaceae versus 1\% in Wild fish. Vibrio were more abundant in captive juvenile common snook than wild and wild-acclimated fish [4]; thus, RAS select for Vibrio in the fish skin microbiota. Increased nutrient input may allow for greater proliferation of these $r$-strategists, while ultraviolet light, ozone, and copper sulfate reduced bacterial competition for space and nutrients. Some fish exposed to copper exhibit immunosuppression and increased susceptibility to Vibrio pathogens [35, 36]. High (40 $\mathrm{ppm}$ ) concentrations of copper reduce virulence in some vibrios [37], whereas lower concentrations trigger production of copper detoxifying compounds, enabling copper resistance [38] that allows colonization, immune avoidance, and lysis of host immune cells, thereby enhancing virulence of the microbe [39]. Copper resistance mechanisms in the Vibrionaceae may explain their enrichment and persistence in copper sulfate-treated fish. As copper may induce virulence, it is vital to maintain a copper level that is non-toxic to the fish to prevent immunosuppression and other physiological damage [13] that can increase fish disease susceptibility. Culturing on TCBS indicated a decrease in the relative abundance of sucrose-fermenting Vibrio in Captive fish as compared to Wild fish. As sucrose is a disaccharide composed of glucose and fructose, a reduction in the proportion of bacteria capable of fermenting this sugar supports the PICRUSt results indicating a decrease in mean relative frequency of glycolysis and fructose/mannose metabolism in Captive fish. It should be noted that the salt concentration in the media used in this study was not equal to the salinity of the rearing environment of the fish and this likely influenced the number of cultivable bacteria and Vibrio, as well as the proportion of sucrose fermenters. Oliver et al. [40] did not find a correlation between total bacterial counts, total Vibrio counts, or percent sucrose fermenters and salinity in water. However, there was a negative correlation between total bacteria and salinity in plankton samples, as well as a negative correlation between sucrose fermenters and salinity in oysters. Other studies indicate a positive correlation between total Vibrio counts and salinity [41, 42]. As our samples were host-associated, we may have counted fewer bacteria and sucrose fermenters if the salinity of the media used was $3.5 \%$.

Total Vibrio plate counts and sequencing data suggest females may harbor more vibrios than males in Captive1 and Captive-2 individuals, but the cause is unclear. The scraping technique used to collect mucus may amass greater amounts of water from larger individuals (Captive females were $3.5 \pm 2.7 \mathrm{~kg}, 66.4 \pm 19.3 \mathrm{~cm}$ and Captive males were $0.8 \pm 0.2 \mathrm{~kg}, 45.4 \pm 3.3 \mathrm{~cm}$ ) and future studies should standardize counts to protein concentration to account for this variation. Literature does suggest a potential role of immune response in the differing vibrio abundances between sexes, as male sea bass (Dicentrarchus labrax) launched a greater IgM response to injected heat-inactivated Vibrio anguillarum than females [43]. If this stronger antibody defense occurs in common snook, males may be better equipped to prevent Vibrio colonization within the mucosal microbiota. A formal study designed to detect differences between sexes would be required to determine if this is a true pattern or a random sampling effect resulting from small sample size. 
RAS decreased bacterial diversity and evenness in the snook external microbiota compared to Wild environments, a trend that is commonly reported [4, 44-47]. It is clear that conditions in captivity influence hostassociated microbial communities, in part from increased nutrient input and water disinfection as described previously, but also from altered diets which can influence both the gut and skin microbiota [48]. The phylum Bacteroidetes was greatly reduced following copper sulfate treatment then increased over time in captivity, nearly recovering to levels measured in Wild fish. The Bacteroidetes were replaced primarily with Firmicutes which remained abundant throughout the sampling periods. Firmicutes and Bacteroidetes play important roles in polysaccharide catabolism; however, Bacteroidetes are generalists for many simple and complex glycans as compared to the more specialized Firmicutes [49]. The gastrointestinal tract of cultured yellowtail kingfish (Seriola lalandi) and Atlantic salmon (Salmo salar) contained greater abundances of Firmicutes than their wild counterparts $[7,50]$ and it was suggested that selection for Firmicutes during captivity represents the limited diet encountered in aquaculture systems [50]. As diet alters the gut and skin microbiota [48], the availability of a smaller variety of polysaccharides in captive diets may be reflected in the fish skin microbiota. Copper treatment could also select for Firmicutes as Gram-positive bacteria have high resistance to copper toxicity [51]. Thus, our data indicates the potential for diet and copper sulfate together to influence the skin microbiota at a high taxonomic level.

As demonstrated in previous studies, the bacteria inhabiting the surrounding water likely influenced the skin microbiota composition of adult snook [47, 52], but the variability attributable to changes in water communities cannot be determined as concurrent water samples were only taken at the Captive-3 sampling period (see Additional info 3). Previous studies have indicated that aquaculture systems alter water microbial community composition $[9,47,50]$, and it is likely that water microbiota change over time in RAS $[18,53]$ even without chemical treatment. Therefore, we recognize that there was likely a random water effect that influenced the fish skin microbiota in this study. However, samples from Captive- 3 and other studies $[47,52,54,55]$ indicate the mucosal microbiota harbors a unique bacterial composition in comparison to the surrounding environment in RAS and natural environments that is influenced by host parameters including mucosal composition and host immune response as well as contaminants. Therefore, we suggest the observed changes among environments and sampling periods is not explained solely by random water effects, but also by copper sulfate and unmeasured physiological changes that occur to fish in captivity.
The greater abundance of Cyanobacteria in Wild fish is likely explained by the high abundance of Synechococcus in marine environments [56] and its ability to adapt to lower salinities found in bays [57]. Our snook, sampled from Terra Ceia Bay, FL, are likely to encounter and associate with this genus. Also abundant in Wild fish was HIMB11 of the Roseobacter clade (Alphaproteobacteria) which is enriched in waters during blooms of Synechococcus [58], perhaps explaining the cooccurrence of these two groups. Although Synechococcus and Clade Ia (SAR11, Alphaproteobacteria) appear as transient groups that decreased over time in our RAS, HIMB11 remained at low abundances in Captive fish and may represent a core member of the snook microbiota, using a wide variety of compounds for energy [59] to adjust to differing environmental conditions.

Copper sulfate treatment selected for metal-tolerant bacteria, and bacterial biomarkers of the fish mucosal microbiota may act as indicators of heavy metal pollution as suggested by Montenegro et al. [60]. Catenococcus (enriched in Captive-1) and Halomonas and Marinobacter (enriched in Captive-2) were found in high abundances downstream of a metal-polluted estuary where many copper tolerant isolates were collected [61] and may be bioindicators of copper contamination. Additionally, the genera Halomonas and Marinobacter positively correlate with environmental pollutants, such as polycyclic aromatic hydrocarbons and metals [60] and perform denitrification using a nitrite reductase (nirK) that requires and is positively correlated with copper [62]. Shewanella were abundant in Captive-1 and decreased over time in captivity. Members of this genus express copper resistance genes [63] and bioabsorb copper ions [64], perhaps leading to its enrichment immediately post treatment. Deinococcus, known for tolerance to high levels of radiation and oxidation, followed a similar pattern to Shewanella. Genes that regulate copper homeostasis in Deinococcus also provide protection against oxidative stress [65], and may allow survival at early captive sampling points when copper levels were still relatively high. Due to its presence in negative controls in other studies [28], we cannot rule out the possibility that the sequences attributed to Deinococcus are contaminants obtained during sample processing. Upon reanalysis after removing potential contaminants, Cetobacterium was enriched in Captive-2. This genus increased in the gut microbiota of common carp following 8 weeks of copper exposure [66] suggesting it may be copper resistant. Methylotrophic bacteria were indicative of Captive-2 fish, including two OTUs identified as Methylophaga and one within the family Methylophagaceae. The Methylophaga bacteria use amicyanin, a copper-containing protein, as an electron acceptor during degradation of methylamines [67], and these 
microbes may aid in removal of copper during chemical depuration. Selection for the aforementioned taxa suggests reflection of environmental pollution within the fish mucosal microbiota, and due to the intimate relationship between the microbiota and immune defenses, these microorganisms may serve as non-lethal biomarkers for contaminant exposure and fish health.

Despite vast taxonomic differences between Wild and Captive-3 mucosal microbiota, predicted functionality better resembled wild-type following time in captivity. The increase in Bacteroidetes in Captive-3 fishes was defined by the family Saprospiraceae, capable of degrading complex carbon sources [68]. Also enriched in Captive-3 individuals were members of the genus Bacillus, which are often used as probiotics in fishes to increase disease resistance and boost immune function $[18,69]$ and likely represent commensal or mutualistic members of the community as they are often isolated from apparently healthy fishes [31-33]. Butanoate metabolism, which was decreased following copper sulfate treatment, recovered to and exceeded that of wild individuals after 2 years in captivity. Butanoate is a short chain fatty acid well-recognized for its prebiotic effects in cultured fish as it provides energy to cells, boosts immune response $[70,71]$, and increases amino acid availability [72], relating to greater lysine metabolism detected in Captive-3 snook. It is important to point out that results from PICRUSt analysis are predictive and therefore should be interpreted as hypotheses [26, 73]. The ability to predict community function using this analysis is limited by the genomic information currently available for each taxon. In addition, it assumes that the genes are transcribed and translated. In order to test the hypotheses generated during PICRUSt analysis, the presence of the functional genes should be confirmed with metagenomics. Their expression in the community can be investigated using transcriptomics, and their translation into functional proteins investigated with proteomics. Formal studies should be conducted using these technologies to confirm the restoration of beneficial community function following copper sulfate treatment.

Although the specific members of the skin microbiota vary considerably upon transition to captivity, predictive functional redundancy within the microbial communities may allow recovery of mutualistic microbes and metabolic pathways vital to fish health. These shifts indicate that, despite the lower diversity and greatly altered taxonomic structure of captive snook external bacterial assemblages, a microbiota capable of degrading complex carbon sources, competitively excluding pathogens, boosting immunity, and producing beneficial short chain fatty acids is present in captive broodstock. The beneficial potential of the captive microbiota and the longterm survival and reproductive success of common snook broodstock suggest major alterations of the fish microbiota can occur without obvious detriments to fish health in RAS.

Currently, at least 20 fish species are grown in aquaculture for stocking purposes, with greater than 3.5 billion individuals released in 2018 [74]. In order to maintain genetic diversity and fitness upon release, it is recommended that local, wild broodstock be regularly added to the captive breeding population [75]. Therefore, maintaining fish health during transition of wild individuals to captive environments is an ongoing concern for these programs. As mucosal microbiota play a vital role in fish health via competitive exclusion of pathogens and stimulation of immune function, unraveling the connections between aquaculture practices and microbiota structure and function can help farmers anticipate and prevent potential health issues associated with captivity [76]. Microbiota alterations at the parent level could influence the bacterial communities associated with eggs and larvae through vertical transmission of bacteria [77]. As early microbial assemblages play a role in tissue development [78], immune function [79], and behavior [80], a captive microbiota may influence physiology of the fish and impact their ability to survive upon release. It is also possible that different microbiota structures result in similar physiological development, perhaps due to host genetic factors and/or functional redundancy among bacteria, and these drastic community changes do not negatively impact the individual. In order to increase understanding of host-microbe relationships in aquaculture, we recommend future studies that incorporate -omics technologies to address microbiota function and host physiology during transition from wild to captivity, as well as the impacts of a captive microbiota on larval development.

\section{Supplementary Information}

The online version contains supplementary material available at https://doi. org/10.1186/s42523-021-00085-5.

Additional file 1. LEfSe results indicating OTUs discriminatory for each sampling period. Average and standard error of the mean are included for each OTU identified by LEfSe analysis as discriminatory between sampling periods. This file includes results from original analysis ('Original Data' tab) and analysis after removal of potential contaminants ('Potential Contaminants Removed' tab).

Additional file 2. Bacterial taxa identified in this study that contain potential fish pathogens. Average and standard error of the mean are included for each potentially pathogenic bacterial genus present in sequencing analysis, listed by sampling period. Taxa included were determined using the following source: B. Austin and D. A. Austin. 2012 Bacterial Fish Pathogens: Disease of Farmed and Wild Fish, 5th edition. Springer, New York. 652 pp.

Additional file 3. Data analysis files including water samples taken during sampling period Captive-3 and including year of capture for captive snook. A. Relative abundance of phyla; B. Multidimensional scaling 
(MDS) plot; C. Heat map indicating relative abundance of discriminatory OTUs.

Additional file 4. Data analysis files excluding potential contaminants. A. Relative abundance of phyla; B. Muldimensional scaling (MDS) plot; C Heat map indicating relative abundance of discriminatory OTUs.

\section{Abbreviations}

KEGG: Kyoto Encyclopedia of Genes and Genomes; LEfSe: Linear discriminant effect size; OTU: Operational taxonomic unit; PERMANOVA: Permutational analysis of variance; PICRUSt: Phylogenetic investigation of communities by reconstruction of unobserved states; RAS: Recirculating aquaculture system; SIMPER: Similarity percentages; TCBS: Thiosulfate citrate bile salts sucrose; TSA + S: Tryptic soy agar supplemented with $2 \% \mathrm{NaCl}$

\section{Acknowledgments}

The authors wish to thank members of the Fisheries Ecology \& Enhancement and Marine \& Freshwater Aquaculture programs at Mote Marine Laboratory for aiding in wild fish collection, as well as volunteers and interns from Mote Marine Laboratory that participated in sampling events.

\section{Authors' contributions}

KM and MR were responsible for all aspects of fish collections and husbandry. MR aided in collection of mucosal samples. NL and AT collected all mucosal samples and were major contributors in writing the manuscript. NL performed culture-dependent analyses. AT performed culture-independent microbiota analyses and analyzed and interpreted all data. All authors read and approved the final manuscript.

\section{Funding}

This project was funded in part by the NSF-REU program (OCE \#1460800) and the Mote Postdoctoral Research Fellowship program.

\section{Availability of data and materials}

The microbiota sequence data generated during the current study are available in the Sequence Read Archive repository (www.ncbi.nlm.nih.gov/ sra/), SRA study accession PRJNA664785.

\section{Ethics approval}

All applicable international, national, and/or institutional guidelines for the care and use of animals were followed. All procedures performed in studies involving animals were in accordance with the ethical standards of the institution outlined in Mote Marine Laboratory's Animal Welfare Assurance (A4219-01). All experimental protocols were approved by Mote Marine Laboratory's Animal Care and Use Committee (IACUC Approval No. 18-10KM1 and 16-05-KM1). Snook broodstock were sampled under Special Activity License SAL-15-1491 A-ABC.

\section{Consent for publication}

Not applicable.

\section{Competing interests}

The authors declare that they have no competing interests.

\section{Author details}

${ }^{1}$ Marine Immunology Program, Mote Marine Laboratory, 1600 Ken Thompson Parkway, Sarasota, FL 34236, USA. ${ }^{2}$ Biology Department, Wabash College, 301 West Wabash Avenue, Crawfordsville, IN 47933, USA. ${ }^{3}$ Current affiliation: Medical Scientist Training Program, University of Miami Miller School of Medicine, 1600 NW 10th Avenue, Miami, FL 33101, USA. ${ }^{4}$ Directorate of Fisheries and Aquaculture, Mote Aquaculture Research Park, 874 WR Mote Way, Sarasota, FL 34240, USA.

\section{Received: 13 October 2020 Accepted: 18 February 2021} Published online: 02 March 2021

\section{References}

1. Uribe C, Folch H, Enriquez R, Moran G. Innate and adaptive immunity in teleost fish: a review. Vet Med (Praha). 2011;56:486-503 http://vri.cz/docs/ vetmed/56-10-486.pdf.
2. Gomez D, Sunyer JO, Salinas I. The mucosal immune system of fish: the evolution of tolerating commensals while fighting pathogens. Fish Shellfish Immunol. 2013;35:1729-39. https://doi.org/10.1016/j.fsi.2013.09.032.

3. Larsen A, Tao Z, Bullard SA, Arias CR. Diversity of the skin microbiota of fishes: evidence for host species specificity. FEMS Microbiol Ecol. 2013;85: 483-94.

4. Tarnecki AM, Brennan NP, Schloesser RW, Rhody NR. Shifts in the skinassociated microbiota of hatchery-reared common snook Centropomus undecimalis during acclimation to the wild. Microb Ecol. 2018;77:770-81.

5. Merrifield DL, Rodiles A. The fish microbiome and its interactions with mucosal tissues. In: Mucosal Health in Aquaculture; 2015. p. 273-95.

6. Tarnecki AM, Burgos FA, Ray CL, Arias CR. Fish intestinal microbiome: diversity and symbiosis unraveled by metagenomics. J Appl Microbiol. 2017; 123:2-17.

7. Ramírez C, Romero J. The microbiome of Seriola lalandi of wild and aquaculture origin reveals differences in composition and potential function. Front Mi. 2017:8:1844.

8. Ramírez C, Romero J. Fine flounder (Paralichthys adspersus) microbiome showed important differences between wild and reared specimens. Front Microbiol. 2017:8:1-12

9. Attramadal KJK, Truong TMH, Bakke I, Skjermo J, Olsen Y, Vadstein O. RAS and microbial maturation as tools for K-selection of microbial communities improve survival in cod larvae. Aquaculture. April 2014;2014(432):483-90.

10. Rurangwa $E_{1}$ Verdegem MCJ. Microorganisms in recirculating aquaculture systems and their management. Rev Aquacult. 2015;7:117-30.

11. Schryver DP, Vadstein O. Ecological theory as a foundation to control pathogenic invasion in aquaculture; 2014

12. Muller RG, Taylor RG. The 2013 stock assessment update of common snook, Centropomus undecimalis. St. Petersburg: Fish and Wildlife Conservation Commission; 2013.

13. Yanong RPE. Use of copper in marine aquaculture and aquarium systems. 2013. http://edis.ifas.ufl.edu/fa165.

14. Tom-Petersen A, Brandt KK, Nybroe O, Jørgensen NOG. Copper bioavailability and impact on bacterial growth in flow-through rainbow trout aquaculture systems. Aquaculture. 2011;322-323:259-62. https://doi. org/10.1016/j.aquaculture.2011.09.038.

15. Qian D, Xu C, Chen C, Qin JG, Chen L, Li E. Toxic effect of chronic waterborne copper exposure on growth, immunity, anti-oxidative capacity and gut microbiota of Pacific white shrimp Litopenaeus vannamei. Fish Shellfish Immunol. 2020;100(February):445-55. https://doi.org/10.1016/j.fsi.2 020.03.018.

16. Mohammed HH, Arias CR. Potassium permanganate elicits a shift of the external fish microbiome and increases host susceptibility to columnaris disease. Vet Res. 2015;46:82. https://doi.org/10.1186/s13567-015-0215-y.

17. Tarnecki AM, Rhody NR. Microbiota of common snook Centropomus undecimalis larvae exhibiting high mortality. Aquacult Res. 2017;48:5693-8.

18. Tarnecki AM, Wafapoor M, Phillips RN, Rhody NR. Benefits of a Bacillus probiotic to larval fish survival and transport stress resistance. Sci Rep. 2019; 9:4892.

19. Rhody NR, Puchulutegui C, Taggart JB, Main KL, Migaud H. Parental contribution and spawning performance in captive common snook Centropomus undecimalis broodstock. Aquaculture. 2014;432:144-53. https:// doi.org/10.1016/j.aquaculture.2014.04.022.

20. Tarnecki AM, Brennan NP, Schloesser RW, Rhody NR. Shifts in the skinassociated microbiota of hatchery-reared common snook Centropomus undecimalis during acclimation to the wild. Microb Ecol. 2018;77(3):770-781.

21. Kozich JJ, Westcott SL, Baxter NT, Highlander SK, Schloss PD. Development of a dual-index sequencing strategy and curation pipeline for analyzing amplicon sequence data on the miseq illumina sequencing platform. Appl Environ Microbiol. 2013;79:5112-20.

22. Quast C, Pruesse E, Yilmaz P, Gerken J, Schweer T, Yarza P, et al. The SILVA ribosomal RNA gene database project: improved data processing and webbased tools. Nucleic Acids Res. 2013;41:590-6.

23. DeSantis TZ, Hugenholtz P, Larsen N, Rojas M, Brodie EL, Keller K, et al. Greengenes, a chimera-checked 16S rRNA gene database and workbench compatible with ARB. Appl Environ Microbiol. 2006;72:5069-72.

24. Clarke KR, Gorley RN. PRIMER v6: User Manual/Tutorial. Plymouth: Primer-e; 2006.

25. Segata N, Izard J, Waldron L, Gevers D, Miropolsky L, Garrett WS, et al. Metagenomic biomarker discovery and explanation. Genome Biol. 2011;12: R60. https://doi.org/10.1186/gb-2011-12-6-r60. 
26. Langille MG, Zaneveld J, Caporaso JG, McDonald D, Knights D, Reyes JA, et al. Predictive functional profiling of microbial communities using $16 \mathrm{~S}$ rRNA marker gene sequences. Nat Biotechnol. 2013;31:814-21.

27. Parks DH, Tyson GW, Hugenholtz P, Beiko RG. STAMP: statistical analysis of taxonomic and functional profiles. Bioinformatics. 2014;30:3123-4.

28. Salter S, Cox M, Turek E, Calus S, Cookson W, Moffatt M, et al. Reagent and laboratory contamination can critically impact sequence-based microbiome analyses. BMC Biol. 2014;12:1-12.

29. Glassing A, Dowd SE, Galandiuk S, Davis B, Chiodini RJ. Inherent bacterial DNA contamination of extraction and sequencing reagents may affect interpretation of microbiota in low bacterial biomass samples. Gut Pathog 2016:8:1-12.

30. Austin B, Austin DA. Bacterial fish pathogens. Disease of farmed and wild fish. 5th ed; 2012.

31. Arias CR, Koenders $K$, Larsen AM. Predominant bacteria associated with red snapper from the northern Gulf of Mexico. J Aquat Anim Health. 2013;25: 281-9.

32. Austin B. The bacterial microflora of fish, revised. ScientificWorldJournal. 2006;6:931-45

33. Hakkimane SS, Rathod JL. Isolation and enumeration of bacterial flora in false trevally, Lactarius lactarius of Karwar, central west coast of India. Indian J Geo-Marine Sci. 2011;40:583-6.

34. Lima Junior EM, Bandeira T d JPG, Miranda MJB d, Ferreira GE, Parente EA, Piccolo NS, et al. Characterization of the microbiota of the skin and oral cavity of Oreochromis niloticus. J Heal Biol Sci. 2016;4:193.

35. Yeh ST, Liu CH, Chen JC. Effect of copper sulfate on the immune response and susceptibility to Vibrio alginolyticus in the white shrimp Litopenaeus vannamei. Fish Shellfish Immunol. 2004;17:437-46.

36. Baker RJ, Knittel MD, Fryer JL. Susceptibility of Chinook salmon, Oncorhynchus tshawytscha (Walbaum), and rainbow trout, Salmo gairdneri Richardson, to infection with Vibrio anguillarum following sublethal copper exposure. J Fish Dis. 1983;6:267-75.

37. Nakayama T, Nomura N, Matsumura M. The effect of copper concentration on the virulence of pathogenic Vibrio harveyi. J Appl Microbiol. 2007;102: 1300-6

38. Harwood-Sears V, Gordon AS. Copper-induced production of copperbinding supernatant proteins by the marine bacterium Vibrio alginolyticus. Appl Environ Microbiol. 1990;56:1327-32.

39. Vanhove AS, Rubio TP, Nguyen AN, Lemire A, Roche D, Nicod J, et al. Copper homeostasis at the host vibrio interface: lessons from intracellular vibrio transcriptomics. Environ Microbiol. 2016;18:875-88.

40. Oliver JD, Warner RA, Cleland DR. Distribution of Vibrio vulnificus and other lactose-fermenting vibrios in the marine environment. Appl Environ Microbiol. 1983;45:985-98.

41. Eiler A, Johansson M, Bertilsson S. Environmental influences on Vibrio populations in northern temperate and boreal coastal waters (Baltic and Skagerrak seas). Appl Environ Microbiol. 2006;72:6004-11.

42. Hsieh JL, Fries JS, Noble RT. Dynamics and predictive modelling of Vibrio spp. in the Neuse River Estuary, North Carolina, USA. Environ Microbiol. 2008;10:57-64.

43. Coeurdacier $\mathrm{JL}$, Pepin JF, Fauvel C, Legall P, Bourmaud AF, Romestand B. Alterations in total protein, $\lg \mathrm{M}$ and specific antibody activity of male and female sea bass (Dicentrarchus labrax L., 1758) sera following injection with killed Vibrio anguillarum. Fish Shellfish Immunol. 1997;7:151-60.

44. Eichmiller JJ, Hamilton MJ, Staley C, Sadowsky MJ, Sorensen PW. Environment shapes the fecal microbiome of invasive carp species. Microbiome. 2016;4:44. https://doi.org/10.1186/s40168-016-0190-1.

45. Hennersdorf P, Mrotzek G, Abdul-Aziz MA, Saluz HP. Metagenomic analysis between free-living and cultured Epinephelus fuscoguttatus under different environmental conditions in Indonesian waters. Mar Pollut Bull. 2016;110: 726-34.

46. Dehler CE, Secombes CJ, Martin SAM. Environmental and physiological factors shape the gut microbiota of Atlantic salmon parr (Salmo salar L.). Aquaculture. 2017;467:149-57. https://doi.org/10.1016/j.aquaculture.2016.07.017.

47. Webster TMU, Consuegra S, Hitchings M, de Leaniz CG. Interpopulation variation in the Atlantic salmon microbiome reflects environmental and genetic diversity. Appl Environ Microbiol. 2018;84:1-14.

48. Landeira-Dabarca A, Sieiro C, Alvarez M. Change in food ingestion induces rapid shifts in the diversity of microbiota associated with cutaneous mucus of Atlantic salmon Salmo salar. J Fish Biol. 2013;82:893-906.
49. Cockburn DW, Koropatkin NM. Polysaccharide degradation by the intestinal microbiota and its influence on human health and disease. J Mol Biol. 2016; 428:3230-52. https://doi.org/10.1016/j.jmb.2016.06.021.

50. Lavoie C, Courcelle M, Redivo B, Derome N. Structural and compositional mismatch between captive and wild Atlantic salmon (Salmo salar) parrs gut microbiota highlights the relevance of integrating molecular ecology for management and conservation methods. Evol Appl. 2018; In press. https:// doi.org/10.1111/eva.12658.

51. Santo CE, Morais PV, Grass G. Isolation and characterization of bacteria resistant to metallic copper surfaces. Appl Environ Microbiol. 2010;76:1341-8.

52. Larsen AM, Bullard SA, Womble M, Arias CR. Community structure of skin microbiome of Gulf killifish, Fundulus grandis, is driven by seasonality and not exposure to oiled sediments in a Louisiana salt marsh. Microb Ecol. 2015;70:534-44.

53. Vestrum Rl, Attramadal KJK, Winge P, Li K, Olsen Y, Bones AM, et al. Rearing water treatment induces microbial selection influencing the microbiota and pathogen associated transcripts of cod (Gadus morhua) larvae. Front Microbiol. 2018;9:851.

54. Stevens $J \mathrm{~L}$, Olson JB. Bacterial communities associated with lionfish in their native and invaded ranges. Mar Ecol Prog Ser. 2015;531:253-62.

55. Chiarello M, Villéger $S$, Bouvier $C$, Bettarel $Y$, Bouvier T. High diversity of skinassociated bacterial communities of marine fishes is promoted by their high variability among body parts, individuals and species. FEMS Microbiol Ecol. 2015;91(November):fiv061.

56. Flombaum P, Gallegos JL, Gordillo RA, Rincón J, Zabala LL, Jiao N, et al. Present and future global distributions of the marine Cyanobacteria Prochlorococcus and Synechococcus. P Natl Acad Sci USA. 2013;110:9824-9.

57. Partensky F, Blanchot J, Vaulot D. Differential distribution and ecology of Prochlorococcus and Synechococcus in oceanic waters: a review. Bull I'Institut Océanographique Monaco. 1999;19:457-75 http://cat.inist.fr/?aModele= afficheN\&cpsidt=1218663.

58. Li J, Chen Z, Jing Z, Zhou L, Li G, Ke Z, et al. Synechococcus bloom in the Pearl River Estuary and adjacent coastal area-with special focus on flooding during wet seasons. Sci Total Environ. 2019;692:769-83. https://doi.org/10.1 016/j.scitotenv.2019.07.088.

59. Durham BP, Grote J, Whittaker KA, Bender SJ, Luo H, Grim SL, et al. Draft genome sequence of marine alphaproteobacterial strain HIMB11, the first cultivated representative of a unique lineage within the Roseobacter clade possessing an unusually small genome. Stand Genomic Sci. 2014;9:632-45. https://doi.org/10.4056/sig.

60. Montenegro D, Astudillo-García C, Hickey T, Lear G. A non-invasive method to monitor marine pollution from bacterial DNA present in fish skin mucus. Environ Pollut. 2020;263:114438. https://doi.org/10.1016/j.envpol.2020.114438.

61. Sheeba VA, Anas A, Jasmin C, Vincent M, Parameswaran PS. Response of particle-associated bacteria to long-term heavy metal contamination in a tropical estuary. World J Microbiol Biotechnol. 2020;36:1-10. https://doi. org/10.1007/s11274-020-02842-1.

62. Liu J, Li C, Jing J, Zhao P, Luo Z, Cao M, et al. Ecological patterns and adaptability of bacterial communities in alkaline copper mine drainage. Water Res. 2018;133:99-109. https://doi.org/10.1016/j.watres.2018.01.014.

63. Toes ACM, Daleke MH, Kuenen JG, Muyzer G. Expression of copA and cusA in Shewanella during copper stress. Microbiology. 2008;154:2709-18.

64. Mamba BB, Dlamini NP, Mulaba-Bafubiandi AF. Biosorptive removal of copper and cobalt from aqueous solutions: Shewanella spp. put to the test. Phys Chem Earth. 2009;34:841-9.

65. Zhao Z, Zhou Z, Li L, Xian X, Ke X, Chen M, et al. A copper-responsive gene cluster is required for copper homeostasis and contributes to oxidative resistance in Deinococcus radiodurans R1. Mol Biosyst. 2013;10:2607-16.

66. Meng XL, Li S, Qin CB, Zhu ZX, Hu WP, Yang LP, et al. Intestinal microbiota and lipid metabolism responses in the common carp (Cyprinus carpio L.) following copper exposure. Ecotoxicol Environ Saf. 2018;160(April):257-64. https://doi.org/10.1016/j.ecoenv.2018.05.050.

67. Shmareva MN, Doronina NV, Tarlachkov SV, Vasilenko OV, Trotsenko YA. Methylophaga muralis Bur 1, a haloalkaliphilic methylotroph isolated from the Khilganta soda lake (Southern Transbaikalia, Buryat Republic). Microbiol (Russian Fed). 2018;87:33-46.

68. Mcllroy S, Nielsen PH. The Saprospiraceae. In: The Prokaryotes: Other Major Lineages of Bacteria and the Archaea; 2006. p. 863-89.

69. Kuebutornye FKA, Abarike ED, Lu Y. A review on the application of Bacillus as probiotics in aquaculture. Fish Shellfish Immunol. 2019:87(November 2018):820-8. https://doi.org/10.1016/j.fsi.2019.02.010. 
70. Hoseinifar SH, Sun YZ, Caipang CM. Short-chain fatty acids as feed supplements for sustainable aquaculture: an updated view. Aquacult Res. 2017:48:1380-91.

71. Abdel-Latif HMR, Abdel-Tawwab M, Dawood MAO, Menanteau-Ledouble S, El-Matbouli M. Benefits of dietary butyric acid, sodium butyrate, and their protected forms in aquafeeds: a review. Rev Fish Sci Aquac. 2020;28:421-48. https://doi.org/10.1080/23308249.2020.1758899.

72. Robles R, Lozano AB, Sevilla A, Márquez L, Nuez-Ortín W, Moyano FJ. Effect of partially protected butyrate used as feed additive on growth and intestinal metabolism in sea bream (Sparus aurata). Fish Physiol Biochem. 2013;39:1567-80.

73. Langille MGI. Exploring linkages between taxonomic and functional profiles of the human microbiome. mSystems. 2018;3:e00163-17.

74. USDA. 2018 Census of aquaculture. 2017 Census Agric. 2019;3:AC-17-SS-2. https://www.agcensus.usda.gov/Publications/2017/Online_Resources/Aqua culture/. Accessed 23 Jan 2021.

75. Lorenzen K, Leber KM, Blankenship HL. Responsible approach to marine stock enhancement: an update. Rev Fish Sci. 2010;18:189-210.

76. Minich JJ, Poore GD, Jantawongsri K, Johnston C, Bowie K, Bowman J, Knight R, Nowak B, Allen EE. Microbial ecology of Atlantic salmon (Salmo salar) hatcheries: impacts of the built environment on fish mucosal microbiota. Appl Environ Microbiol. 2020;86:e00411-20.

77. Legrand TPRA, Wynne JW, Weyrich LS, Oxley APA. A microbial sea of possibilities: current knowledge and prospects for an improved understanding of the fish microbiome. Rev Aquac. 2020;12(2):1101-34.

78. Bates JM, Mittge E, Kuhlman J, Baden KN, Cheesman SE, Guillemin K. Distinct signals from the microbiota promote different aspects of zebrafish gut differentiation. Dev Biol. 2006;297:374-86.

79. Hansen GH, Olafsen JA. Bacterial interactions in early life stages of marine cold water fish. Microb Ecol. 1999;38:1-26.

80. Davis DJ, Bryda EC, Gillespie CH, Ericsson AC. Microbial modulation of behavior and stress responses in zebrafish larvae. Behav Brain Res. 2016;311: 219-27.

\section{Publisher's Note}

Springer Nature remains neutral with regard to jurisdictional claims in published maps and institutional affiliations.

Ready to submit your research? Choose BMC and benefit from:

- fast, convenient online submission

- thorough peer review by experienced researchers in your field

- rapid publication on acceptance

- support for research data, including large and complex data types

- gold Open Access which fosters wider collaboration and increased citations

- maximum visibility for your research: over $100 \mathrm{M}$ website views per year

At $\mathrm{BMC}$, research is always in progress.

Learn more biomedcentral.com/submissions 